\title{
INSIGHTS
}

\section{Family Reflections: Micropreemies and ROP}

\author{
Andrea Mullenmeister ${ }^{1}$ \\ Pediatric Research (2018) 84:600-601; https://doi.org/10.1038/s41390-018-0159-9
}

In July 2012, my son was born more than 4 months early at 23 weeks gestation. I barely had time to wrap my head around the fact that I was a mom, let alone the fact that my son had only a $4 \%$ chance of healthy survival.

Dreams of bringing a fat baby home from the hospital vanished. The neonatal intensive care unit (NICU) was our new nightmare. Instead of lullabies, the piercing sounds of the NICU became the soundtrack to motherhood and the stench of antiseptic overtook the smell of soft baby skin. Machines were keeping our son alive. They were constantly beeping and alarming, warning us of the literal and precious balance between life and death. Wires and tubes hid my baby's face, but I could see blood pumping through his translucent skin.

My husband and I watched helplessly as nurses poked and prodded our baby. I was allowed to touch my son for a split second-but only with one finger. The nurse cautioned me to be very gentle so I didn't accidentally rip his skin.

We became numb from the fear that our son would die before we could take him home. It seemed there was a new hurdle to clear every day: blood transfusions, sepsis, heart problems, gut problems, and brain scans. Doctors told us he might not ever be able to walk or talk. I figured that would be ok-we could work with that. At least he would be able to hear and see and we could explore the world through those senses.

So, when we got the results from my son's first Retinopathy of Prematurity (ROP) eye exam, I was terrified.

I remember standing by Jaxson's isolette, describing everything I saw out the window: the clear blue sky, the trees dancing in the breeze, and the bright sunshine. I wanted my son to know what it was like outside the walls of the NICU, but I didn't know if he would ever be able to see these things for himself. Jaxson had just been diagnosed with Zone I, Stage III ROP with PLUS Disease and it was threatening to take his eyesight.

Jaxson was referred to a ROP specialist. The doctor was kind, informative, and very skilled at her job. We trusted her and we knew she would help us make the right decisions to save Jaxson's eyesight. However, I had a hard time finding information online about ROP that I could understand, especially when I was nervous and stressed out about the diagnosis.

I was surprised at the lack of information available about ROP that is written in common language that a parent can easily understand. The handout we got from our hospital had no information other than the date and time of Jaxson's next eye appointment and a check-mark next to the words "Zone 1," "Stage III," and "Plus." What did this mean?

I tried asking the nurse and she said that ROP is common and not to worry. That did not help.

I tried contacting the ROP specialist but she was in surgery.
I tried contacting the specialist's assistant, but she was at another hospital, and was not scheduled to come back to our hospital until the next week.

I had no way of getting the information I needed and I sat in the room alone with my son for hours upon hours, wondering and worrying about this new diagnosis.

A few days later, the ophthalmologist performed another exam. Based on what she saw, she recommended the new-atthe-time treatment of injecting a chemotherapy drug called Avastin into Jaxson's eyes. (Our doctor did not tell us this at the time! I think she was worried we would hear the word "chemotherapy" and freak out.) I recognized the name of the drug because my mother had received this type of chemotherapy for breast cancer. I did my own research and realized there was no concrete information available about the drug or the side-effects for this purpose. By piecing together different articles, I learned that Avastin is a tumor-starving (antiangiogenic) therapy that prevents the growth of blood vessels. The drug would work on Jax's eyes because it would target and destroy the enlarged and twisted vessels (the Plus Disease) and allow healthy blood vessels to grow into the other areas of his retinas.

This sounded good in theory, but I was worried about the lack of long-term data for the treatment. The risk of the unknown outweighed the risk of blindness for our family and we chose to do the treatment.

The Avastin injections were administered bedside in the NICU the next morning. The procedure took one minute! While the procedure itself was quick, the process was stressful for me and my baby. Jaxson's heartrate was through the roof and his oxygen levels dipped. After the procedure, I immediately did Kangaroo Care with my son to help comfort him. Luckily, he stabilized and was able to rest comfortably for the rest of the day.

Thankfully, the Avastin injections cured my son's Plus Disease. Jaxson showed positive progress immediately when the healthy blood vessels reached Zone 2 of his eye, but then the vessels stopped growing. Our doctor warned us that laser surgery was still a possibility.

Jaxson's eyes were carefully monitored for any changes. He got weekly eye exams until he was released from the NICU and they continued after we got home. The clinic was $40 \mathrm{~min}$ from home. I lugged my newborn, his oxygen tank, and his diaper bag into a waiting room filled with coughing, sniffling people in the middle of RSV season once a week for 3 months. It was incredibly stressful.

When my son was 6 months old actual ( 2 months adjusted), the disease began progressing again. The blood vessels in his retina began bleeding and showing signs (again) of Plus Disease. It was

${ }^{1}$ Pediatric Researchhttps://www.nature.com/pr

Correspondence: Andrea Mullenmeister (info@pedres.org)

Received: 14 August 2018 Accepted: 14 August 2018

Published online: 23 October 2018 
time for laser surgery. We were more comfortable with laser surgery at this point because the Avastin injections had cured the disease in Zone 1; he would only need laser surgery in Zones 2 and 3. The laser surgery took approximately $30 \mathrm{~min}$ and was performed under general anesthesia. Jaxson's eyes were slightly puffy and red after surgery, but he did not seem bothered by it at all. After the surgery, Jax had monthly follow-ups with his ROP specialist.

My preemie was discharged from his ROP specialist and referred to a pediatric ophthalmologist for continuing care when he was 1 year old actual. Jaxson is 6 years old now and he sees the pediatric ophthalmologist every 3-6 months. Jaxson is showing signs of myopia (nearsightedness), strabismus (crossed eyes), amblyopia (lazy eye) which could be lasting effects from the ROP, the injections, or the laser surgery.
I am grateful Jax's eyesight was saved!

The biggest deficit in the field is the lack of parent-appropriate literature and web sites that plainly describe and explain the different treatments, side effects, warning signs, and lasting effects of the different ROP treatments. I would like to see more work done to "boil down" lengthy research articles into easy to understand language-kind of the like a "Parent Abstract." I have a college education and English is my first language and I still found it difficult to read and understand the available information. I can't imagine what it would be like if I had low-literacy skills or if English was my second language.

I think researchers are doing a fantastic job studying cuttingedge treatments and approaches, but the missing piece is how that information trickles down to families. 